\title{
Religious and Spiritual Coping and Quality of Life Among Patients With Emphysema in the National Emphysema Treatment Trial
}

\author{
Marquisha R Green PhD, Charles F Emery PhD, Elizabeth Kozora PhD, \\ Philip T Diaz MD, and Barry J Make MD
}

\begin{abstract}
BACKGROUND: Although prior research indicates that religious and spiritual coping is associated with positive health outcomes, few studies have examined religious and spiritual coping among patients with emphysema. OBJECTIVE: To describe the utilization of religious and spiritual coping and its relationship to quality of life among patients with emphysema, in a 2-year longitudinal follow-up study. METHODS: Forty patients with emphysema (mean age $63.5 \pm 6.0 \mathrm{y}, 8$ women) who participated in the National Emphysema Treatment Trial were matched on age, sex, race, and education with 40 healthy individuals recruited from the community. We conducted baseline assessment of overall coping strategies, psychological functioning, quality of life, pulmonary function, and exercise capacity, and we assessed overall coping strategies and religious and spiritual coping at 2-year follow-up. RESULTS: Ninety percent of the patients with emphysema considered themselves at least slightly religious and spiritual. The patients reported using both negative religious coping (eg, questioning God) and positive religious coping (eg, prayer) more than the healthy control subjects at follow-up. However, greater use of religious and spiritual coping was associated with poorer illness-related quality of life. CONCLUSIONS: Patients with emphysema appear to use various coping strategies in responding to their illness. Future research should investigate if patients using religious and spiritual coping would benefit from interventions to address emotional distress and reduced quality of life. Key words: emphysema; pulmonary rehabilitations; coping; depression; anxiety; quality of life; religiosity; spirituality; National Emphysema Treatment Trial. [Respir Care 2011;56(10):1514-1521. (C) 2011 Daedalus Enterprises]
\end{abstract}

\section{Introduction}

Emphysema is associated with reduced quality of life and elevated symptoms of depression and anxiety. ${ }^{1-2} \mathrm{~Pa}-$ tients may use mental coping strategies (eg, problem-solving to address difficult situations and to reinterpret stressful situations as more favorable and less threatening) to adjust to chronic illness, thereby improving quality of life and psychological functioning. ${ }^{3-5}$ Among patients with chronic lung disease, some coping strategies (eg, seeking

Drs Green and Emery are affiliated with the Department of Psychology, and Drs Emery and Diaz are affiliated with the Department of Internal Medicine, The Ohio State University, Columbus, Ohio. Dr Kozora is affiliated with the Department of Psychosocial Medicine, and Dr Make is affiliated with the Department of Medicine, National Jewish Health, University of Colorado School of Medicine, Denver, Colorado.

This research was partly supported by National Institutes of Health grants R01-HL63761, F31-GM078715, M01-RR00051, and M01-RR00034. The authors have disclosed no conflicts of interest. social support from family and friends) are associated with positive well-being and some coping strategies (eg, tendency to avoid problems) are associated with worse symptoms of depression and anxiety, and reduced quality of life. $6-8$

Religiosity and spirituality are coping strategies that are predictive of physical and mental health outcomes among chronically ill patients. ${ }^{9-13}$ However, studies suggest that religious and spiritual coping strategies are both positively Dr Green presented a version of this paper at the annual meeting of the
Society of Behavioral Medicine, held March 26-29, 2008, San Diego,
California.

The authors have disclosed no conflicts of interest.

Correspondence: Charles F Emery PhD, Department of Psychology, The Ohio State University, 1835 Neil Avenue Mall, Columbus OH 43210. E-mail: emery.33@osu.edu.

DOI: $10.4187 /$ respcare.01105 
and negatively associated with health outcomes. ${ }^{9-13}$ Religiosity can be defined as the beliefs, values, practices, and rituals of a particular faith. ${ }^{12}$ Spirituality is distinct from religiosity in that it addresses ultimate questions about life's meaning, is more subjective, and is less visible and measurable than religiosity. ${ }^{12,14,15}$ Among patients with end-stage pulmonary disease, religious and spiritual coping is associated with higher levels of social functioning, but also with greater psychological distress and disability. ${ }^{16,17}$ Very few studies have examined religious and spiritual coping among patients with emphysema. In other patient groups (eg, cancer), greater use of religiosity and spirituality has been associated with better health and wellbeing. ${ }^{18}$ Thus, there is reason to believe that religiosity and spirituality may be beneficial for the well-being of patients with chronic lung disease.

See the Related Editorial on Page 1627

The primary goal of this study was to examine the utilization of religious and spiritual coping among patients with emphysema who participated in the National Emphysema Treatment Trial (NETT). We investigated change in coping over a 2-year follow-up period, and evaluated religious and spiritual coping as a predictor of quality of life, psychological functioning, and pulmonary functioning. We hypothesized that patients with emphysema would utilize multiple coping strategies, including religious and spiritual coping, more than healthy individuals, and that positive religious and spiritual coping (eg, seeking support from God), and behaviors such as forgiveness would be associated with better health and quality of life among patients, but that negative religious and spiritual coping (eg, questioning God) would be associated with worse health and quality of life.

\section{Methods}

This study was approved by The Ohio State University Biomedical Institutional Review Board (1999H0132) and the National Jewish Health Institutional Review Board (HS211). Participants completed informed consent prior to participation, in addition to the prior informed consent for the ancillary study.

\section{Subjects}

Participants were recruited in the context of a NETT ancillary study of cognitive functioning among patients with emphysema. ${ }^{19}$ The NETT ancillary study was conducted at The Ohio State University, Columbus, Ohio, and at National Jewish Health, Denver, Colorado. Participants in the NETT were randomly assigned to one of two groups:

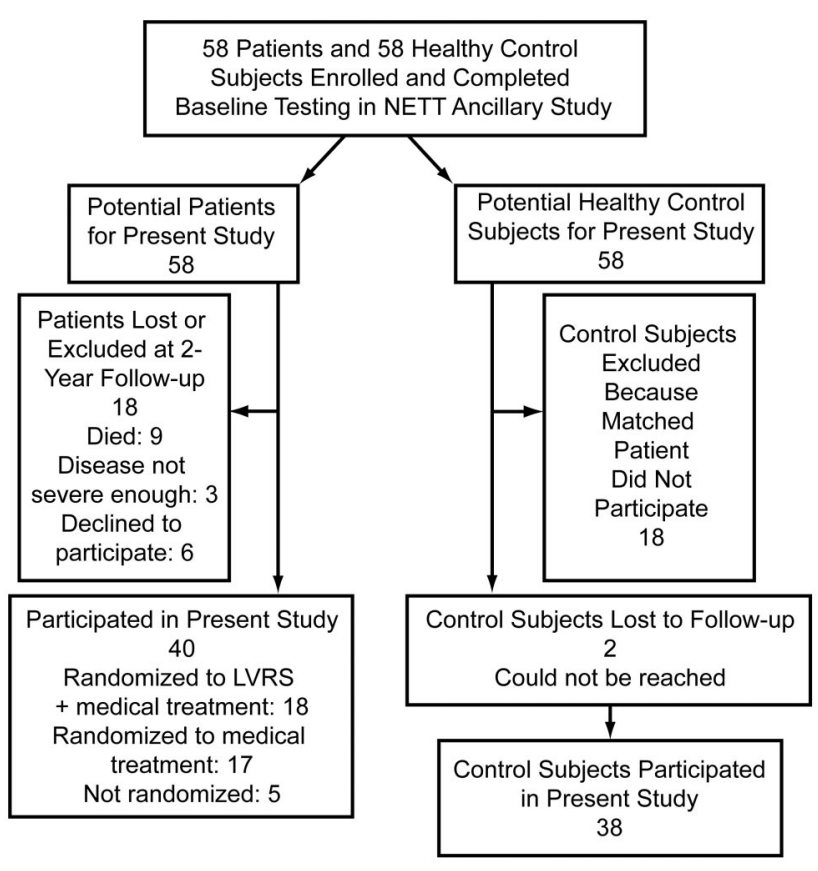

Fig. 1. Flow chart. NETT = National Emphysema Treatment Trial. lung-volume-reduction surgery = lung-volume-reduction surgery.

lung-volume-reduction surgery plus medical treatment, or medical treatment only. The ancillary study examined the neuropsychological functioning of the patients in the 2 groups. Fifty-eight patients at the 2 study sites completed the standard NETT exercise rehabilitation medical treatment, including baseline testing, 6-10 weeks of exercise rehabilitation, and post-rehabilitation testing prior to becoming eligible for randomization into the experimental groups.

All 58 participants were re-contacted 2 years after their initial baseline assessment, to recruit them for participation in this study. Of the 58 patients, 9 had died, 3 no longer met inclusion criteria because their disease was not severe enough, and 6 declined to participate. Thus, this longitudinal study included 40 patients: 18 from the lungvolume-reduction surgery and medical treatment group, 17 from the medical treatment group, and 5 who had dropped out of the NETT prior to randomization (Fig. 1).

Each patient was matched by age ( \pm 2 years), sex, race, and education ( \pm 2 years) to a healthy adult recruited from the community via radio and newspaper announcements. All prospective healthy control participants were evaluated via telephone screening by a research technician to determine age, education history, and medical history of neurologic or psychiatric illness. Thus, we relied on the control participants' self-reports of health status. Healthy control participants were recruited following randomization of each cohort of approximately 15 emphysema patients to ensure that demographics of the healthy control participants matched those of the enrolled emphysema pa- 
Table 1. Subjects

\begin{tabular}{|c|c|c|}
\hline & $\begin{array}{l}\text { Patients With } \\
\text { Emphysema } \\
(n=40)\end{array}$ & $\begin{array}{l}\text { Healthy Matched } \\
\text { Control Subjects } \\
\quad(n=38)\end{array}$ \\
\hline Male, no. & 32 & 31 \\
\hline Female, no. & 8 & 7 \\
\hline Age (y) & $63.5 \pm 6.0$ & $63.5 \pm 4.6$ \\
\hline Education (y) & $12.4 \pm 1.9$ & $13.3 \pm 2.1$ \\
\hline White $(\%)$ & 95 & 95 \\
\hline Married (\%) & 47 & 57 \\
\hline Smoking history (y) & $41.8 \pm 6.7$ & $18.9 \pm 13.4$ \\
\hline $\mathrm{FEV}_{1}(\%$ predicted $)$ & $21 \pm 0.07$ & ND \\
\hline $\mathrm{P}_{\mathrm{aO}_{2}}(\mathrm{~mm} \mathrm{Hg})$ & $61 \pm 12$ & ND \\
\hline $\mathrm{P}_{\mathrm{aCO}_{2}}(\mathrm{~mm} \mathrm{Hg})$ & $44 \pm 6$ & ND \\
\hline 6-min walk distance (m) & $365 \pm 94$ & ND \\
\hline $\begin{array}{l}\text { Maximum oxygen consumption } \\
\text { (L/min) }\end{array}$ & $1.1 \pm 0.2$ & ND \\
\hline Work load (Watts) & $44.7 \pm 21.8$ & ND \\
\hline $\begin{array}{l} \pm \text { values are mean } \pm \text { SD. } \\
\mathrm{ND}=\text { no data collected }\end{array}$ & & \\
\hline
\end{tabular}

tients. The patients and matched healthy controls were primarily older white men (Table 1).

\section{Baseline Assessment}

At baseline, prior to participating in pulmonary rehabilitation, NETT participants completed pulmonary function testing, exercise testing, and self-report questionnaires evaluating psychological well-being, quality of life, and coping. Healthy controls completed self-report questionnaires evaluating psychological well-being, quality of life, and coping, but did not undergo pulmonary function testing or exercise testing.

Pulmonary Function and Exercise Endurance. $\mathrm{P}_{\mathrm{aO}_{2}}$ and $\mathrm{P}_{\mathrm{aCO}}$ were measured at rest while the participant was breathing room air. $\mathrm{FEV}_{1}$ and forced vital capacity were evaluated with standard spirometry, per the American Thoracic Society guidelines. Maximum oxygen consumption and cardiopulmonary endurance were evaluated during cycle ergometry on an $\mathrm{F}_{\mathrm{IO}_{2}}$ of 0.30 , with the work load increasing at increments of 5-10 Watts every minute, until the participant had maximum fatigue or shortness of breath. The 6-minute walk test was conducted per standard procedures (eg, level surface, research staff provided feedback regarding elapsed time and carried the oxygen for the participant if needed). The 6-minute walk test assesses functional capacity for performing daily tasks. Generally, a 6-minute walk distance $<305 \mathrm{~m}$ indicates important functional limitations in a patient with emphysema. ${ }^{20}$

Beck Depression Inventory. The Beck Depression Inventory $^{21}$ consists of 21 items that assess emotional and somatic symptoms of depression. The total score range is 0 to 63 . The Beck Depression Inventory has high internal consistency and discriminant and content validity in clinical and nonclinical populations. ${ }^{21}$ The reliability of the Beck Depression Inventory in this sample was good (Cronbach's alpha $=0.84$ ).

State-Trait Anxiety Inventory. The State-Trait Anxiety Inventory ${ }^{22}$ has been used extensively in research. It includes 20 statements that evaluate how the subject feels "right now, at this moment" (state anxiety), and 20 statements that evaluate how the subject generally feels (trait anxiety). The total score range for these subscales is 20 80. The State-Trait Anxiety Inventory has high reliability and adequate validity for surgical populations. ${ }^{22}$ The internal reliability of the State-Trait Anxiety Inventory in this sample was very good (Cronbach's alpha $=0.90$ ).

St George's Respiratory Questionnaire. St George's Respiratory Questionnaire ${ }^{23}$ is a 76-item disease-specific quality-of-life measure, with a total score and 3 component scores (symptoms, activities, and impact) that reflect pulmonary-disease-induced limitations on daily life. St George's Respiratory Questionnaire has sufficient reliability and validity among pulmonary patients. ${ }^{23}$ The reliability of the St George's Respiratory Questionnaire in this sample was adequate (Cronbach's alpha $=0.63$ ).

Brief COPE Questionnaire. The Brief COPE Questionnaire 24,25 is a 28 -item self-report questionnaire that assesses a broad range of coping strategies. It has 14 subscales and a 2-item religion subscale. The items are on a 4-point Likert scale that ranges from "I haven't been doing this at all" to "I've been doing this a lot." The score range for overall coping, excluding the religious subscale, is $26-$ 104 , and the score range for the religious subscale is $2-8$. The Brief COPE Questionnaire is reliable and valid. ${ }^{24,25}$ The reliability of the overall Brief COPE Questionnaire in this sample was very good (Cronbach's alpha $=0.84$ ), as was the reliability of the 2-item religion subscale ( $r=0.87$ ).

The healthy control participants completed all of the above measures except the St George's Respiratory Questionnaire.

\section{Follow-up Assessment}

Two years after the baseline assessment, all participants were contacted via telephone and were mailed a follow-up packet of 3 questionnaires to assess general coping strategies and religious and spiritual coping: the Brief COPE Questionnaire, the Brief Multidimensional Measure of Religiousness and Spirituality, and the Brief Religious Coping Questionnaire. The subjects with emphysema were also sent the Religion and Health Questionnaire. The 2-year 
follow-up did not include pulmonary function testing, exercise testing, or questionnaires on well-being or quality of life. The follow-up packet included a self-addressed, stamped return envelope.

The Brief Multidimensional Measure of Religion and Spirituality ${ }^{14}$ is a 40 -item self-report measure of religiosity and spirituality for use in health research. Four of its subscales were relevant in this study: forgiveness (eg, whether an individual feels forgiven by the transcendent and forgives him/herself); private religious practices (eg, prayer); organized religious practices (eg, church attendance); and overall self-ranking of religious and spiritual coping (ie, degree to which the individual feels religious and spiritual). All the subscale items are on Likert scales, but the scale range differs across the subscales. The forgiveness subscale (3 items) is rated on a 4-point Likert scale, with responses ranging from "Always or almost always" to "Never or almost never." Scores range from 3 to 12. The private religious practices subscale (5 items) is primarily rated on an 8-point Likert scale, with responses ranging from "More than once a day" to "Never." However, one item is rated on a 5-point Likert scale, with responses ranging from "At all meals" to "Never." Scores on the forgiveness subscale range from 5 to 37 . The organized religious practices subscale ( 2 items) is rated on a 6-point Likert scale, with responses ranging from "More than once a week" to "Never." Scores range from 2 to 12. The overall self-ranking subscale (2 items) is rated on a 4-point Likert scale, with responses ranging from "Very religious or spiritual" to "Not at all religious or spiritual." Scores range from 2 to 8 . Higher scores on all the Brief Multidimensional Measure of Religion and Spirituality subscales indicate greater religiosity and spirituality. The Brief Multidimensional Measure of Religion and Spirituality has adequate reliability and validity among adults. ${ }^{14}$ The reliabilities of the private religious practices $(r=0.84)$ and organized religious practices $(r=0.86)$ subscales were very good, and the reliabilities for forgiveness (Cronbach's alpha $=0.59$ ) and overall self-ranking subscales (Cronbach's alpha $=0.67$ ) were acceptable for this study.

The Brief Religious Coping Questionnaire ${ }^{26}$ is a 14item self-report questionnaire that assesses the extent to which the respondent utilizes religious strategies to cope with stress. It consists of two 7-item subscales (positive religious coping and negative religious coping), with each item rated on a 4-point Likert scale ranging from "A great deal" to "Not at all." The scores for each subscale range from 0 to 21. The Brief Religious Coping Questionnaire has reliability and validity in hospitalized patients. ${ }^{26}$ The reliability of the Brief Religious Coping Questionnaire in this sample was adequate (positive religious coping Cronbach's alpha $=0.95$, negative religious coping Cronbach's alpha $=0.63)$.
The Religion and Health Questionnaire is a 2-item questionnaire developed for this study to retrospectively assess the types of religious and spiritual strategies participants found most useful in coping with pulmonary disease. The instrument asked, "In coping with your pulmonary disease, what aspects of religiosity and spirituality, if any, have been most useful to you?" Participants were instructed to choose one or more of the following responses: "None. I have not relied on religiosity/spirituality in coping with my pulmonary disease." "Prayer," "Congregational support," "Watching religious programs," "Reading the Bible or other religious literature," "Attendance at religious services," and "Other, please list." The proportion of individuals who utilized each strategy was calculated. The questionnaire also assessed the degree to which participants perceived that their own religious and spiritual coping strategies had changed over time. The instrument asked, "For each item circled above, indicate below how much your use of that strategy changed during your participation in the NETT." For each type of religious and spiritual coping strategy, participants indicated "More", "Same", "Less, or "Not applicable." Proportions of change were calculated for each coping strategy.

\section{Statistical Analysis}

All statistical analyses were conducted with statistics software (SAS 8e, SAS Institute, Cary, North Carolina). Prior research indicated that age, sex, income, and marital status may be confounded with the use of religious and spiritual coping, especially during stressful situations, ${ }^{27}$ so we used Pearson product moment correlations and analysis of variance to assess the association between religious and spiritual coping and age, sex, and marital status. There was no significant association.

Because subjects were recruited from 2 sites, we used analysis of variance to evaluate the baseline differences between the participants from the 2 sites. Participants at The Ohio State University were older $(P<.001)$, more likely to be married $(P=.02)$, more likely to have higher $\mathrm{P}_{\mathrm{aO}_{2}}(P<.001)$, more likely to have lower $\mathrm{P}_{\mathrm{aCO}_{2}}(P<.001)$, and more likely to have lower exercise endurance $(P=.048)$ than patients at National Jewish Health. Because of those differences, site was included as a control variable in all analyses of outcome variables.

We used analysis of covariance to examine differences between the patients and the healthy subjects, covarying site. We conducted repeated-measures analysis of covariance to examine the change in overall coping strategies and religious and spiritual coping. We evaluated differences in individual coping strategies only in the presence of a difference in the overall coping score. We conducted hierarchical linear regression analyses to examine psychological predictors of religious and spiritual coping among 
patients, controlling for site in all analyses. We conducted 10 hierarchical regression analyses: 2 indicators of psychological well-being $\times 5$ religious and spiritual coping outcomes. Each of the 5 religious and spiritual coping strategies (private religious practice, organized religious practices, forgiveness, positive religious coping, and negative religious coping) was first regressed on site, in step 1, followed by one of the psychological well-being indicators (anxiety, depression) in step 2. A Bonferroni correction for multiple comparisons resulted in a $P<.005$ utilized to indicate statistical significance.

Similarly, we conducted hierarchical linear regression analyses to examine physiological predictors of religious and spiritual coping among patients, controlling for site in all analyses. Each of the 5 religious and spiritual coping strategies was regressed on site, in step 1 , followed by one of the physiological indicators (percent-of-predicted $\mathrm{FEV}_{1}$, $\mathrm{P}_{\mathrm{aO}_{2}}, \mathrm{P}_{\mathrm{aCO}_{2}}$, 6-min walk distance, maximum oxygen consumption, and work load) in step 2. Thus, we conducted 30 hierarchical regression analyses (6 pulmonary-function indicators $\times 5$ outcomes). A Bonferroni correction for multiple comparisons resulted in a $P<.0015$ utilized to indicate statistical significance.

We also conducted hierarchical linear regression analyses to evaluate religious coping as a predictor of physiological functioning, psychological well-being, and quality of life. For all regressions, site (The Ohio State University vs National Jewish) was entered as a predictor in the first step, followed by religious coping (assessed with the Brief COPE Questionnaire) in the second step. We conducted 10 regressions, including 6 physiological outcomes (percent-of-predicted $\mathrm{FEV}_{1}, \mathrm{P}_{\mathrm{aO}_{2}}, \mathrm{P}_{\mathrm{aCO}_{2}}$, 6-min walk distance, maximum oxygen consumption, and work load), 2 psychological outcomes (anxiety, depression), and 2 quality-of-life outcomes (mental component and physical component). A Bonferroni correction for multiple comparisons resulted in a $P<.005$ utilized to indicate statistical significance.

\section{Results}

The patients with emphysema had severely impaired pulmonary function (see Table 1). There were no significant differences in pulmonary functioning between the lung-volume-reduction-surgery group and the medical treatment group.

At baseline, religious coping, as measured with the Brief COPE Questionnaire, was not associated with pulmonary functioning or with psychological functioning, as reflected in measures of depression and anxiety. Religious coping was associated with poorer disease-specific quality of life $(r=0.24, P=0.03)$, as measured with the St George's Respiratory Questionnaire (higher score indicates poorer quality of life). In particular, subscale analyses indicated that greater religious coping was associated with the activities component $(r=0.31, P=.009)$ and impact component $(r=0.20, P=.059)$ of quality of life.

At baseline, overall coping, as measured with the Brief COPE Questionnaire, was significantly higher among the patients than among the matched healthy control subjects $(P<.001)$ (Table 2). Analyses of COPE subscales revealed that patients reported using more active coping (eg, taking active steps to remove a stressor or alleviate its effects, $P<.001$ ), emotional support (eg, obtaining moral support, $P<.001$ ), instrumental support (eg, seeking advice, $P<.001$ ), and acceptance (eg, accepting the reality of the stressful situation, $P<.001)$. However, at baseline the religious and spiritual coping of the patients did not differ from that of the healthy control subjects.

Repeated-measures analysis of covariance of the COPE scores revealed a time by group interaction for the coping summary score $(P=.02)$. Tests of simple effects indicated that overall coping increased in the healthy control group, but did not change among the patients with emphysema. Analysis of COPE subscales revealed time by group interactions for positive reframing $(P=.04)$, planning $(P=.02)$, and humor $(P<.003)$. The healthy subjects increased their use of planning, but the emphysema patients decreased their use of positive reframing and humor. There was no interaction effect for religious coping on the COPE, but there was a significant time effect $(P=.03)$, which appeared to reflect increased use of religious coping, primarily among patients with emphysema, between baseline and follow-up.

At 2-year follow-up, $2.5 \%$ considered themselves very religious and spiritual, $45 \%$ of patients with emphysema considered themselves moderately religious and spiritual, $45 \%$ considered themselves slightly religious and spiritual, and $7.5 \%$ did not consider themselves religious and spiritual, as reflected in the overall self-ranking subscale of the Brief Multidimensional Measure of Religion and Spirituality. Most patients reported utilization of one or more of the religious coping strategies. As indicated in response to the Religion and Health Questionnaire, 80\% reported coping with their pulmonary condition by using one or more aspects of religiosity and spirituality, especially prayer (73\%), attending religious services (33\%), congregational support (23\%), and watching religious programs and reading religious literature such as the Bible (18\%). Based upon retrospective self-report of religious and spiritual coping, $37 \%$ of the patients reported utilizing more prayer at the 2-year follow-up than at baseline. However, the patients reported no other changes in the utilization of religious and spiritual coping at the 2-year follow-up (ie, no change in congregation support, watching religious programs, reading religious literature, or church attendance). 
Table 2. Coping Strategies

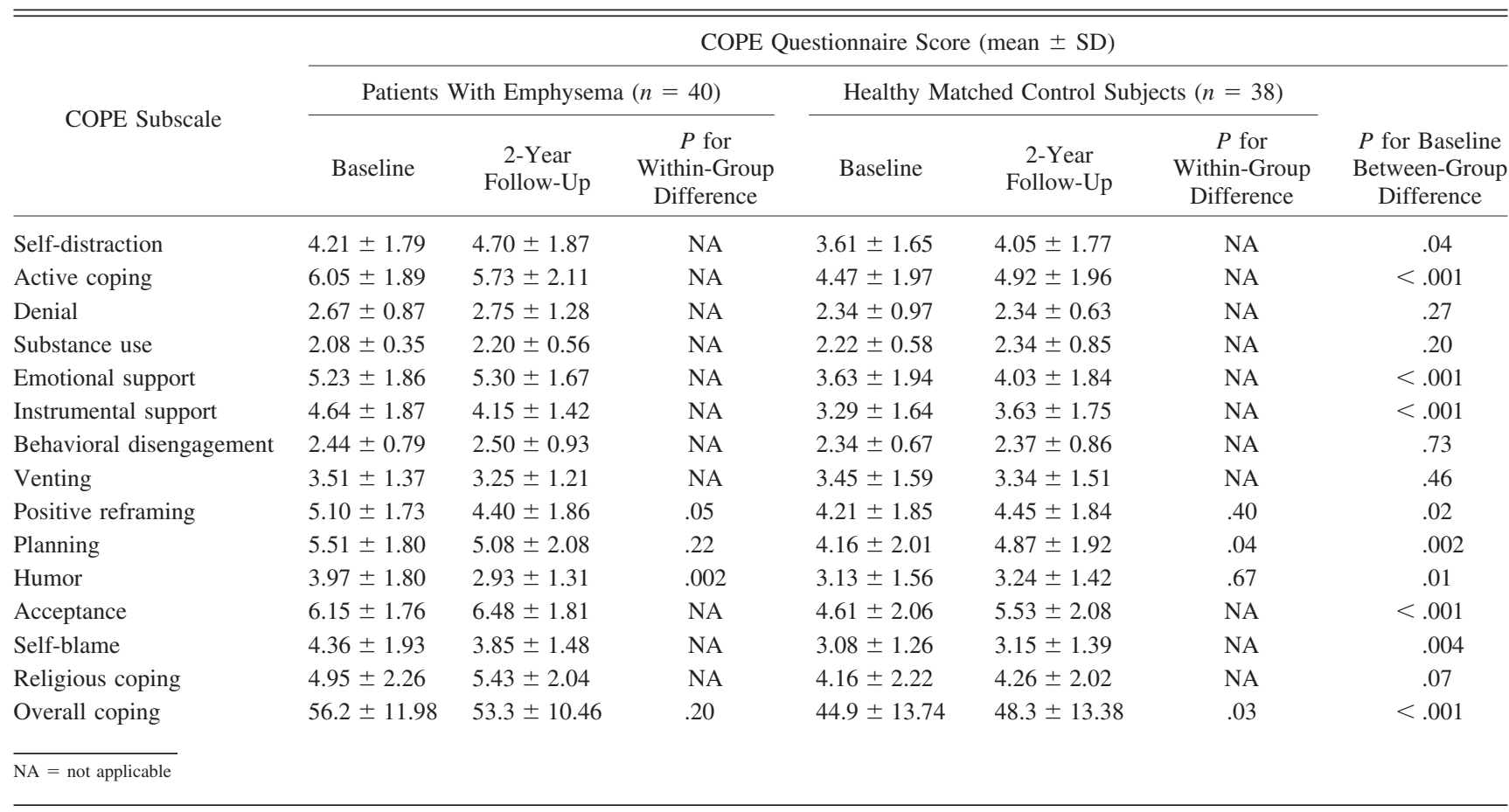

Table 3. Religious and Spiritual Coping at Follow-up

\begin{tabular}{lcc}
\hline \hline \multirow{2}{*}{$\begin{array}{l}\text { Religious or Spiritual Coping Variable } \\
\text { Forgiveness }\end{array}$} & $\begin{array}{c}\text { COPE Questionnaire Score (mean } \pm \text { SD) } \\
\text { Emphysema } \\
(n=40)\end{array}$ & $\begin{array}{c}\text { Healthy Matched } \\
\text { Control Subjects } \\
(n=38) *\end{array}$ \\
\hline Private religious practices & $1.71 \pm 0.52$ & $1.74 \pm 0.66$ \\
Organizational religiosity & $4.26 \pm 1.61$ & $5.04 \pm 1.58$ \\
Overall self-ranking of religious/spiritual coping & $4.28 \pm 1.45$ & $4.09 \pm 1.70$ \\
Positive religious coping & $2.38 \pm 0.70$ & $2.33 \pm 0.82$ \\
Negative religious coping & $9.90 \pm 5.18$ & $6.89 \pm 6.56$ \\
& $1.90 \pm 2.20$ & $0.74 \pm 1.18$ \\
* Data from 2 control subjects are not included because those subjects were not available at 2-year follow-up. & .86 \\
\hline
\end{tabular}

At follow-up, the patients reported using negative religious coping (questioning God, $P=.004$ ), as measured with the Brief Religious Coping Questionnaire, more than did the healthy control subjects (Table 3). Patients and healthy controls did not differ in their use of other religious coping strategies.

Regression analyses indicated that psychological functioning (ie, depression, anxiety), disease-specific quality of life, pulmonary functioning, and exercise capacity of NETT patients at baseline did not predict religious and spiritual coping, as measured with the Brief Religious Coping Questionnaire and the Brief Multidimensional Measure of Religion and Spirituality, at 2-year follow-up.

\section{Discussion}

Patients with emphysema reported using more overall coping strategies (eg, active coping) than did healthy control subjects, although patients and healthy controls reported using similar levels of religious coping. Eighty percent of the patients with emphysema used religiosity and spirituality as coping strategies. Private religious practices and forgiveness were the most utilized religious or spiritual coping strategies, and negative religious coping was the least utilized religious or spiritual coping strategy. Patients reported primarily using prayer to deal with their pulmonary disease, and approximately half of the patients 
who used prayer to deal with their pulmonary disease indicated that their use of prayer had increased over the 2-year longitudinal follow-up. Consistent with prior research, ${ }^{28,29}$ patients utilized both negative and positive religious coping strategies simultaneously.

There was no association between religious and spiritual coping and better psychological well-being, which is consistent with data from patients with end-stage lung disease. ${ }^{16}$ In contrast, a higher level of religious coping was associated with limitations in physical activity and greater disease impact. These results contrast with prior data, which indicated a positive association between religious and spiritual coping and well-being in other patients groups. ${ }^{18} \mathrm{Al}-$ though our findings may further indicate inconsistency in the association between health and religion and spirituality, ${ }^{30}$ the chronicity of health problems may be a relevant factor. The progressive nature of a disease such as emphysema differs sharply from many acute medical or surgical problems. In the context of a chronic condition such as emphysema, religious and spiritual coping is likely to increase rather than decrease as the disease progresses and health status diminishes, resulting in a negative association of religious and spiritual coping with quality of life.

Although patients with emphysema utilized less humor and positive reframing (ie, looking at a stressful situation in positive terms) at 2-year follow-up, their overall use of coping strategies remained the same at follow-up. The stress of chronic illness may make it difficult for patients to find humor in their situation or to look at the situation in a positive light. However, at follow-up, the patients' use of humor and reframing did not differ from that of the healthy controls, so it appears that the patients continued to use these strategies at a level consistent with that of matched peers.

In contrast to prior research, we found no association between religious and spiritual coping and pulmonary function. ${ }^{31}$ However, it is likely that the patients in the present study had already experienced substantial pulmonaryfunction decline, so variability in pulmonary function was greatly restricted in this sample, and an association with religious and spiritual coping would be less likely.

\section{Conclusions}

This study included only a limited assessment of religious coping (the 2-item religion subscale of the COPE) at baseline. Fortunately, more comprehensive measures of religious and spiritual coping were available at the 2-year follow-up. Overall, our results confirm relatively frequent use of religious and spiritual coping among patients with emphysema, and indicate that religious coping is utilized more among patients than among matched healthy individuals. Although religiosity and spirituality do not necessarily play a role in patients' healthcare decisions, it appears that assessment of religiosity and spirituality among patients with emphysema may help to increase understanding of coping strategies. In addition, these data suggest that higher levels of religious and spiritual coping may not be associated with reduced distress or enhanced quality of life. Thus, patients who report using religiosity and spirituality to cope with their emphysema may require additional treatment to address emotional distress and impaired quality of life. Further research is needed to evaluate the utility of additional behavioral or medical interventions among patients already using religious and spiritual coping to cope with emphysema.

\section{REFERENCES}

1. Gudmundsson G, Gislason T, Janson C, Lindberg E, Hallin R, Ulrik $\mathrm{CS}$, et al. Risk factors for rehospitalization in COPD: role of health status, anxiety, and depression. Eur Respir J 2005;26(3):414-419.

2. Dahlen I, Janson C. Anxiety and depression are related to the outcome of emergency treatment in patients with obstructive pulmonary disease. Chest 2002;122(5):1633-1637.

3. Lazarus RS, Folkman S. Stress, appraisal, and coping. New York: Springer Publishing; 1984.

4. Pargament KI. The psychology of religion and coping. New York: Guilford Press; 1997.

5. Yuet LM, Alexander M, Chun C. Coping and adjustment in Chinese patients with chronic obstructive pulmonary disease. Int J Nurs Stud 2002;39(4):383-395.

6. Hesselink AE, Penninx B, Schlosser M, Wijnhoven HA, van der Windt DA, Kriegsman DM, van Eijk JT. The role of coping resources and coping style in quality of life of patients with asthma or COPD. Qual Life Res 2004;13(2):509-518.

7. McCathie HCF, Spence SH, Tate RL. Adjustment to chronic obstructive pulmonary disease: the importance of psychological factors. Eur Respir J 2002;19(1):47-53.

8. Scharloo M, Kaptein AA, Weinman J, Hazes JM, Willems LN, Bergman W, Rooijmans HG. Illness perceptions, coping and functioning in patients with rheumatoid arthritis, chronic obstructive pulmonary disease and psoriasis. J Psychosom Res 1998;44(5):573-585.

9. Daaleman TP, Perera S, Studenski SA. Religion, spirituality, and health status in geriatric outpatients. Ann Family Med 2004;2(1):4953.

10. Koenig HG, George LK, Titus P. Religion, spirituality, and health in medically ill hospitalized older patients. J Am Geriatr Soc 2004; 52(4):554-562.

11. Koenig HG, George LK, Peterson BL. Religiosity and remission of depression in medically ill older adults. Am J Psychiatry 1998;155(4): 536-542.

12. Koenig HG, McCullough ME, Larson DB. Handbook of religion and health. New York: Oxford University Press; 2001.

13. Dein S, Stygall J. Does being religious help or hinder coping with chronic illness? A critical literature review. Palliat Med 1997;11(4): 291-298.

14. Fetzer Institute. Multidimensional measurement of religiousness/ spirituality use in health research. Michigan: Fetzer Institute; 1999.

15. Miller W. Researching the spiritual dimensions of alcohol and other drug problems. Addiction 1998;93(7):979-991.

16. Burker EJ, Evon DM, Sedway JA, Egan T. Religious coping, psychological distress, and disability among patients with end-stage pulmonary disease. J Clin Psychol Med Settings 2004;11(3):179193. 


\section{Religious and Spiritual Coping and Quality of Life Among Patients With Emphysema}

17. Myaskovsky L, Dew MA, Switzer GE, Hall M, Kormos RL, Goycoolea JM, et al. Avoidant coping with health problems is related to poorer quality of life among lung transplant candidates. Prog Transplant 2003;13(3):183-192.

18. Tix AP, Frazier PA. The use of religious coping during stressful life events: main effects, moderation, and mediation. J Consult Clin Psychol 1998;66(2):411-422.

19. Kozora E, Emery CF, Ellison MC, Wamboldt FS, Diaz PT, Make B. Improved neurobehavioral functioning in emphysema patients following lung volume reduction surgery compared with medical therapy. Chest 2005;128(4):2653-2663.

20. Cooper CB, Storer TW. Exercise testing and interpretation: a practical approach. United Kingdom: Cambridge University Press; 2001.

21. Beck AT. Depression inventory. Pennsylvania: Center for Cognitive Therapy; 1978.

22. Spielberger CD. State-trait anxiety inventory for adults. California: Mind Garden; 1983.

23. Jones PW, Quirk FH, Baveystock CM. A self-complete measure of health status for chronic airflow limitation. Am Rev Respir Dis 1992;145(6):1321-1327.
24. Carver CS, Scheier MF, Weintraub, JK. Assessing coping strategies: a theoretically based approach. J Pers Soc Psychol 1989;56(2):267283

25. Carver, CS. You want to measure coping but your protocol's too long: consider the Brief COPE. Int J Behav Med 1997;4(1):92-100.

26. Pargament KI, Smith BW, Koenig HG, Perez L. Patterns of positive and negative religious coping with major life stressors. J Sci Stud Religion 1998;37(4):710-724.

27. Jenkins RA, Pargament KI. Religion and spirituality as resources for coping with cancer. J Psychosoc Oncol 1995;13(1):51-74.

28. Hills J, Paice JA, Cameron JR, Shott S. Spirituality and distress in palliative care consultation. J Palliat Med 2005;8(4):782-788.

29. Sherman AC, Simonton S, Latif U, Spohn R. Tricot G. Religious struggle and religious comfort in response in illness: health outcomes among stem cell transplant patients. J Behav Med 2005;28(4):359-367.

30. Sloan RP, Bagiella E, Powell T. Religion, spirituality, and medicine. Lancet 1999;353(9153):664-667.

31. Maselko J, Kubzansky L, Kawachi I, Staudenmayer J, Berkman L. Religious service attendance and decline in pulmonary function in a high-functioning elderly cohort. Ann Behav Med 2006;32(3):245-253.

This article is approved for Continuing Respiratory Care Education credit. For information and to obtain your CRCE

(free to AARC members) visit

www.RCJournal.com 